\title{
Actualité de l'humanisme. Mélanges offerts à Serge Stolf, dir. P. DE CAPITANI et C. TERREAUX-SCOTTO
}

\section{Filippo Fassina}

\section{(2) OpenEdition}

\section{Journals}

\section{Edizione digitale}

URL: https://journals.openedition.org/studifrancesi/44838

DOI: 10.4000/studifrancesi.44838

ISSN: 2421-5856

\section{Editore}

Rosenberg \& Sellier

\section{Edizione cartacea}

Data di pubblicazione: 1 août 2021

Paginazione: $357-358$

ISSN: 0039-2944

\section{Notizia bibliografica digitale}

Filippo Fassina, «Actualité de l'humanisme. Mélanges offerts à Serge Stolf, dir. P. DE CAPITANı et c. TeRreauxsсотто», Studi Francesi [Online], 194 (LXV | II) | 2021, online dal 01 septembre 2021, consultato il 15 octobre 2022. URL: http://journals.openedition.org/studifrancesi/44838 ; DOI: https://doi.org/10.4000/ studifrancesi. 44838

Questo documento è stato generato automaticamente il 15 octobre 2022.

\section{(i) $\odot$

Creative Commons - Attribuzione - Non commerciale - Non opere derivate 4.0 Internazionale - CC BYNC-ND 4.0

https://creativecommons.org/licenses/by-nc-nd/4.0/ 


\title{
Actualité de l'humanisme. Mélanges offerts à Serge Stolf, dir. P. DE CAPITANI et C. TERREAUX-SCOTTO
}

\author{
Filippo Fassina
}

\section{NOTIZIA}

Actualité de l'humanisme. Mélanges offerts à Serge Stolf, dir. P. DE CAPITANI et C. TERREAUXsсотто, Paris, Classiques Garnier, 2020, «Rencontres» 449, 356 pp.

1 Gli studi qui riuniti, in omaggio a Serge Stolf, trattano un tema di ampia portata, quello dell'attualità dell'Umanesimo in un percorso che parte dal Medioevo, si sofferma in particolare sul periodo che va dal XIV al XVI sec. e giunge fino alla contemporaneità. In questo contesto, l'Umanesimo è considerato, più che un periodo storico-letterario, «une attitude mentale, une approche qui met au centre de ses préoccupations la nature humaine avec ses qualités, ses défauts, ses passions ainsi que la relation de l'homme avec le monde qui l'entoure» (p. 7). L'elemento centrale che dà coerenza a tutti questi lavori è dunque la rinascita dell'individuo e la sua volontà di emergere al di là del proprio gruppo di appartenenza e, di conseguenza, il desiderio di mettere il proprio talento al servizio della società. Come $\mathrm{i}$ curatori sottolineano incisivamente nell'introduzione, è proprio da questa relazione fra sfera privata e pubblica che nasce la complessità e la ricchezza dell'Umanesimo, inteso appunto come modo di pensare e di relazionarsi con il mondo e con la propria realtà di appartenenza. Un altro aspetto fondamentale, valorizzato da questa miscellanea, è il rapporto costante con le lingue e le culture diverse: questa «ouverture sur le monde, sur d'autres cultures ainsi que sur l'interaction entre genres littéraires, techniques et savoirs divers» è una delle caratteristiche che rende l'Umanesimo così moderno e così attuale. La prima parte del volume è proprio consacrata al rapporto fra le lingue e le culture e dà spazio alle traduzioni e alle rielaborazioni di modelli, attraverso generi letterari diversi. La 
seconda parte si concentra invece sulle biografie e autobiografie, sottolineando così la centralità dell'individuo, grande costante umanista. La terza parte è dedicata alla storia dell'arte ed evidenzia come le arti figurative acquisiscano, grazie all'Umanesimo, un nuovo e straordinario prestigio culturale. La quarta parte offre invece un'analisi approfondita del rapporto fra intellettuali e realtà politica. Questa raccolta fornisce dunque, attraverso un approccio coerente e interdisciplinare, un'analisi di grande interesse su come l'Umanesimo non sia un semplice recupero del passato e della cultura antica, ma un atteggiamento mentale quanto mai attuale e, come ha ben sottolineato proprio Serge Stolf, a cui è dedicato questo lavoro, «une confrontation vivante avec ce passé, créatrice de formes renouvelées, de pensées orientées vers le présent» (p. 18).

2 I lavori contenuti nel presente volume sono i seguenti. Patrizia DE CAPITANI et cécile TERREAUX-SCOTTO, Introduction (pp. 7-18). Première partie. «Transferts linguistiques et culturels»: Jean-Claude ZANCARINI, «Faire épreuve de son style». Comment le "Prince" a été traduit en français au XVI ${ }^{\mathrm{e}}$ et XVII ${ }^{\mathrm{e}}$ siècle (pp. 21-31); Emanuela NANNI, Traduire Pétrarque au début $d u X_{X I I}{ }^{\mathrm{e}}$ siècle aux Pays-Bas. Pourquoi relire Philippe de Maldeghem "translateur» des "Rimes"? (pp. 33-45); Patrizia DE CAPITANI, Le Turc dans deux comédies de Giambattista Della Porta (1535-1615). Entre héritage plautinien et "commedia all'improvviso» (pp. 47-65); sonia PORZI, "Les Épistres de la séraphique Vierge Saincte Catherine de Sienne (1644)", une traduction de Jean Balesdens? (pp. 67-82). Deuxième partie. «Biographie, autobiographie»: Luisa SECCHI TARUGI, Le séjour de Pétrarque à Milan à la cour des Visconti (pp. 85-107); Gérard LUCIANI, Vicissitudes posthumes de Gaspara Stampa (pp. 109-122); Jean-Claude TERNAUX, Michel de Montaigne dans le premier chapitre du Livre III des "Essais" (pp.123-131); Edwige COMOY FUSARO, Quasi-récits des quasi-moi de Carlo Dossi alias Alberto Pisani (pp. 133-143); emmanuel matтiato, Aspects des "fictions de l'écrivain» dans l'œeuvre de Dino Buzzati. Les articles oubliés de la guerre civile italienne (pp. 145-169). Troisième partie. «Art verbal et figuratif»: Johannes BARTUSCHAT, «Giotto è maestro d'ogni cosa». Une note sur les peintres dans la nouvelle de Boccacce à Sacchetti (pp. 173-187); cécile TERREAUX-SCOTTO, Prédication et nouvelle. Quelques observations sur les récits fictifs dans les sermons de Bernardin de Sienne (pp. 189-203); Jean-Louis CHARLET, Sur quelques mètres d'Enea Silvio Piccolomini (pp. 205-211); Ismène COTENSIN, «[...] spero che chi verrà doppo noi arà da scrivere la quarta età del mio volume». De Vasari à Passeri, du modèle à son avatar (pp. 213-225); Sylvie MARTINMERCIER, Théâtre et merveilleux en images. Mangefeu et son Grand théâtre de marionnettes vus per les illustrateurs (pp. 227-238). Quatrième partie. «Les humanistes et la cité»: Stefano PITTALUGA, Éloges de la médecine et médecins ignorants (pp. 241-258); Florence BISTAGNE, Éditer et traduire une correspondance humaniste, enjeux et méthodes. Le cas de Giovanni Pontano (pp. 259-276); Francis GOYET, Le «Discours de la servitude volontaire», ou les misères des gens de cour (pp. 277-289); Gilbert BOSETTI, «Della ragion di stato» de Giovanni Botero. Un anti-machiavélien machiavélique? (pp. 291-306).

3 Segnaliamo qui i saggi che interessano maggiormente il Cinquecento francese, pur evidenziando l'importanza di tutto il volume anche per gli specialisti dell'Umanesimo e del Rinascimento. In particolare, ZANCARINI analizza le tipologie di traduzioni del Principe di Machiavelli nella Francia del XVI e XvII secolo, soffermandosi sugli interventi fatti dagli autori sul modello italiano: addizioni, modifica dell'ordine argomentativo, scelta del ritmo della frase e utilizzo del lessico. TERnAuX si concentra sugli elementi autobiografici presenti nel primo capitolo del III libro degli Essais di Montaigne («De l'utile et de l'honeste»), soprattutto per quanto concerne l'esperienza personale 
utilizzata per le riflessioni sul matrimonio, sulla prudenza in politica e sulla sincerità durante le negoziazioni. GOYET fornisce invece una lettura del Discours de la servitude volontaire di Étienne de La Boétie in parallelo con il De curialium miseriis di Enea Silvio Piccolomini, soffermandosi in particolare sulla parte finale del Discours che descrive le miserie degli uomini di corte. 